\title{
An Association between the Estimated Glomerular Filtration Rate and Carotid Atherosclerosis
}

\author{
Ryuichi Kawamoto, Nobuyuki Ohtsuka, Tomo Kusunoki and Nobukazu Yorimitsu
}

\begin{abstract}
Objective Chronic kidney disease (CKD) is a major public health problem. There is conflicting evidence concerning whether CKD is an independent risk factor for carotid intima-media thickness (IMT).

Patients and Methods The study subjects were 428 men aged $70 \pm 15$ (mean \pm standard deviation) years and 582 women aged $75 \pm 12$ years enrolled consecutively from patients in the Medical Department of Seiyo Municipal Nomura Hospital. Carotid IMT was derived via B-mode ultrasonography and CKD was evaluated by the estimated glomerular filtration rate (eGFR) using the Modification of Diet in Renal Disease Study equation.

Results In men, age $(\mathrm{p}<0.001)$, systolic blood pressure $(\mathrm{p}<0.001)$, antihypertensive drug use $(\mathrm{p}<0.001)$, HDL-C $(\mathrm{p}=0.006)$, LDL-C $(\mathrm{p}=0.004)$, prevalence of diabetes $(\mathrm{p}=0.035)$ and eGFR $(\mathrm{p}<0.001)$ were significantly correlated with carotid IMT. In women, age $(\mathrm{p}<0.001)$, systolic blood pressure $(\mathrm{p}<0.001)$, antihypertensive drug use $(\mathrm{p}<0.001)$, HDL-C $(\mathrm{p}=0.035)$, LDL-C $(\mathrm{p}=0.017)$ and eGFR $(\mathrm{p}<0.001)$ were significantly correlated with carotid IMT. Stepwise multiple linear regression analysis using IMT as an objective variable, adjusted by various factors as explanatory variables, showed that eGFR was a significant independent contributing factor along with known risk factors in men $(\beta,-0.096 ; \mathrm{p}=0.018)$ and women $(\beta,-0.080 ; \mathrm{p}=0.035)$.

Conclusions Our data suggested that eGFR was associated with an increased prevalence of carotid atherosclerosis independent of common cardiovascular risk factors in both men and women.
\end{abstract}

Key words: risk factor, atherosclerosis, renal function, eGFR, carotid artery

(Inter Med 47: 391-398, 2008)

(DOI: 10.2169/internalmedicine.47.0552)

\section{Introduction}

Chronic kidney disease (CKD) is a devastating disease with clinical, economic and ethical dimensions, and is a recently recognized major public health problem. Current guidelines define CKD as kidney damage or glomerular filtration rate (GFR) less than $60 \mathrm{~mL} / \mathrm{min} / 1.73 \mathrm{~m}^{2}$ for 3 months or more, regardless of cause (1). On the basis of clinical practice guidelines established by The Japanese Society of Nephrology, $18.7 \%$ of adults in Japan have CKD, with $4.1 \%$ of these classified with moderate or severe kidney disease (2).

Recent independent studies identified the decline of renal function in patients as an independent predictor of all-cause mortality as well as adverse cardiovascular disease (CVD) events. In a community-based population with pre-existing CVD defined as an estimated GFR (eGFR) of less than 60 $\mathrm{mL} / \mathrm{min} / 1.73 \mathrm{~m}^{2}$, the presence of $\mathrm{CKD}$ has been associated with an increased risk of recurrent CVD outcomes after adjustment for traditional CVD risk factors $(3,4)$. Other studies suggest the absence of an independent predictor between CKD and CVD after adjustment for traditional risk factors $(5,6)$. Some authors demonstrated that increased carotid intima-medial thickness (IMT), which is clinically considered as the surrogate endpoint of CVD, occurs early in the course of $\operatorname{CKD}(7,8)$. These changes are associated with higher CVD risk factors in patients with $\operatorname{CKD}(9,10)$. Limited information is available on whether or not the decline in renal function is an independent risk factor for CVD.

First, this study investigated the decline in renal function and its relation to potential risk factors such as hypertension, 
hyperglycemia and lipids. Secondly, we investigated whether or not there is an independent association of GFR with a direct and early measure of carotid IMT by B-mode ultrasound. To examine these two issues, cross-sectional data from participants were used.

\section{Materials and Methods}

\section{Subjects}

Participants were consecutively enrolled from patients in the Medical Department of Seiyo Municipal Nomura Hospital between June 2000 and February 2007. Patients with a clinical history of severe cardio-renal or nutritional disorders that would affect blood pressure, lipids or glucose metabolism were excluded. Furthermore, we excluded 53 participants (22 men and 31 women) with an eGFR $<30 \mathrm{~mL} / \mathrm{min} /$ $1.73 \mathrm{~m}^{2}$ and enrolled 1,010 patients in this study. There were 428 men aged $70 \pm 15$ (mean \pm standard deviation) years and 582 women aged $75 \pm 12$ years. Informed consent for the procedure was obtained from each patient. All procedures were approved by the Ethics Committee of Seiyo Municipal Nomura Hospital.

\section{Evaluation of risk factors}

Information on demographic characteristics and risk factors was collected using the clinical files in all cases. We measured blood pressure in the right upper arm of patients in a sedentary position using a standard sphygmomanometer or an automatic oscillometric blood pressure recorder. Cigarette smoking was quantified based on daily consumption and duration of smoking. Fasting total cholesterol (T-C), triglycerides (TG), high-density lipoprotein cholesterol (HDLC), fasting blood glucose (FBG), creatinine (enzymatic method) and uric acid levels were measured within 24 hours of admission. Low-density lipoprotein cholesterol (LDL-C) level was calculated by the Friedewald formula (11). Patients with TG levels $\geqq 400 \mathrm{mg} / \mathrm{dL}$ were excluded (12 cases). The presence of diabetes mellitus was defined as a history of treatment for diabetes mellitus. Glomerular filtration rate was estimated by using the following equations: $\mathrm{eGFR}=0.741 \times 175 \times \mathrm{Cr}^{-1.154} \times \operatorname{Age}^{-0.203} \times 0.742$ (for females) $(12$, 13).

\section{Ultrasound image analysis}

An ultrasonograph (Hitachi EUB-565 or Aloka SSD2000) equipped with a $7.5 \mathrm{MHz}$ linear type B-mode probe was used by an ultrasonograph specialist to evaluate sclerotic lesions of the common carotid arteries within two days of blood biochemistry analysis. Patients were in the supine position, and the bilateral carotid arteries were observed obliquely from the anterior and posterior directions. We measured the thickness of the intima-media complex (IMT) on the far wall of the bilateral common carotid artery at about $10 \mathrm{~mm}$ proximal to the bifurcation of the carotid artery. The image at this site is more clearly depicted than that at the near wall $(14,15)$. Wall thickness near the $10 \mathrm{~mm}$ point on the B-mode monitor was also measured. The mean values were used for the analysis.

\section{Statistical analysis}

Statistical analysis was performed using SPSS 10.0J (Statistical Package for Social Science, Inc., Chicago, IL, USA). All values are expressed as means \pm standard deviation, unless otherwise specified. Because the distribution of smoking status, TG and FBG was skewed, it was logarithmically transformed for analysis. Differences among the groups were analyzed by 2-tailed Student's t-test or $\chi^{2}$ test. To investigate the relation between eGFR and various factors, all subjects were divided into three groups based on eGFR (eGFR-1, $\geq 90 \mathrm{~mL} / \mathrm{min} / 1.73 \mathrm{~m}^{2}$; eGFR-2, $60-89 \mathrm{~mL} / \mathrm{min} /$ $1.73 \mathrm{~m}^{2}$; eGFR-3, 30-59 $\mathrm{mL} / \mathrm{min} / 1.73 \mathrm{~m}^{2}$ ). The correlation between the three groups based on eGFR and background parameters was determined by 1-way ANOVA or $\chi^{2}$ test. Correlations between various characteristics and IMT were determined using Pearson's correlation test. Multiple linear regression analysis was used to evaluate the contribution of each risk factor including eGFR for carotid IMT. A value of $\mathrm{p}<0.05$ was considered significant.

\section{Results}

\section{Characteristics of patients by gender}

Table 1 shows the background characteristics by gender. Several characteristics differed between men and women; $\log$ smoking status $(\mathrm{p}<0.001)$, diastolic blood pressure $(\mathrm{p}=$ 0.036), log FBG $(p=0.035)$, serum creatinine $(p<0.001)$, serum uric acid $(\mathrm{p}<0.001)$ and prevalence of ischemic stroke $(\mathrm{p}=0.036)$ were higher in men than in women, whereas age $(\mathrm{p}<0.001)$, antihypertensive drug use $(\mathrm{p}=0.001), \mathrm{T}-\mathrm{C}, \quad(\mathrm{p}<$ $0.001)$, HDL-C $(\mathrm{p}<0.001)$, LDL-C $(\mathrm{p}<0.001)$ and antilipidemic drug use $(p=0.004)$ were higher in women than in men. There were no inter-group differences in BMI, systolic blood pressure, Log TG, prevalence of diabetes and CKD, carotid IMT and the prevalence of ischemic heart disease.

\section{Characteristics of various risk factors of subjects categorized by estimated glomerular filtration rate and gender}

Table 2 shows the value of each cardiovascular risk factor categorized by eGFR in men and women. In men, age $(\mathrm{p}<$ $0.001)$, antihypertensive drug use $(\mathrm{p}<0.001)$, serum creatinine $(\mathrm{p}<0.001)$, serum uric acid $(\mathrm{p}<0.001)$ and the prevalence of atherosclerotic disease $(\mathrm{p}=0.011)$ were higher in the group with lower eGFR, but anitilipidemic drug use ( $\mathrm{p}=$ 0.033 ) was lower in the group with lower eGFR. In women, age $(\mathrm{p}<0.001)$, BMI $(\mathrm{p}=0.009)$, antihypertensive drug use $(p=0.002), \log \mathrm{TG}(\mathrm{p}<0.001)$, serum creatinine $(\mathrm{p}<0.001)$, serum uric acid $(\mathrm{p}<0.001)$ and prevalence of ischemic heart disease $(p=0.025)$ were increased in the group with lower 
Table 1. Characteristics of Subjects Categorized by Gender

\begin{tabular}{|c|c|c|c|}
\hline Characteristic & $\begin{array}{l}\text { Men } \\
\mathrm{n}=428\end{array}$ & $\begin{array}{c}\text { Women } \\
\mathrm{n}=582\end{array}$ & $p$-value* \\
\hline Age (years) & $70 \pm 15$ & $75 \pm 12$ & $<0.001$ \\
\hline Body mass index $\dagger\left(\mathrm{kg} / \mathrm{m}^{2}\right)$ & $22.4 \pm 3.9$ & $22.2 \pm 4.1$ & 0.525 \\
\hline Smoking status $¥$ (pack year) & $23(0-45)$ & $0(0)$ & ------ \\
\hline Log smoking status $₫$ (pack year) & $1.05 \pm 0.73$ & $0.05 \pm 0.26$ & $<0.001$ \\
\hline Systolic blood pressure $(\mathrm{mmHg})$ & $136 \pm 22$ & $136 \pm 20$ & 0.629 \\
\hline Diastolic blood pressure $(\mathrm{mmHg})$ & $78 \pm 13$ & $76 \pm 12$ & 0.036 \\
\hline Antihypertensive drug use, $n$ (\%) & $179(41.8)$ & $303(52.1)$ & 0.001 \\
\hline Total cholesterol (mg/dL) & $171 \pm 43$ & $191 \pm 42$ & $<0.001$ \\
\hline Triglycerides $(\mathrm{mg} / \mathrm{dL})$ & $83(60-115)$ & $81(59-109)$ & ------ \\
\hline Log triglycerides $(\mathrm{mg} / \mathrm{dL})$ & $1.93 \pm 0.22$ & $1.92 \pm 0.20$ & 0.288 \\
\hline HDL-cholesterol (mg/dL) & $50 \pm 18$ & $55 \pm 17$ & $<0.001$ \\
\hline LDL-cholesterol (mg/dL) & $101 \pm 37$ & $117 \pm 35$ & $<0.001$ \\
\hline Antilipidemic drug use, $\mathrm{n}(\%)$ & $17(4.0)$ & $49(8.4)$ & 0.004 \\
\hline Fasting blood glucose (mg/dL) & $116(97-150)$ & $110(93-140)$ & ----- \\
\hline Log fasting blood glucose (mg/dL) & $2.10 \pm 0.15$ & $2.07 \pm 0.14$ & 0.035 \\
\hline Diabetes, n (\%) & $117(27.3)$ & $136(23.4)$ & 0.163 \\
\hline Serum creatinine $(\mathrm{mg} / \mathrm{dL})$ & $0.84 \pm 0.23$ & $0.66 \pm 0.18$ & $<0.001$ \\
\hline Serum uric acid (mg/dl) & $5.5 \pm 1.8$ & $4.7 \pm 1.6$ & $<0.001$ \\
\hline Chronic kidney disease $\S, \mathrm{n}(\%)$ & $137(32.0)$ & $187(32.1)$ & 1.000 \\
\hline Carotid intima-media thickness $(\mathrm{mm})$ & $0.98 \pm 0.24$ & $0.96 \pm 0.21$ & 0.108 \\
\hline Atherosclerotic disease, $\mathrm{n}(\%)$ & $174(40.7)$ & $218(37.5)$ & 0.327 \\
\hline Ischemic stroke, n (\%) & $158(36.9)$ & $178(30.6)$ & 0.036 \\
\hline Ischemic heart disease, $\mathrm{n}(\%)$ & $33(7.7)$ & $56(9.6)$ & 0.313 \\
\hline \multicolumn{4}{|c|}{$\begin{array}{l}\text { Data are means } \pm \text { standard deviation or median (interquartile range). } † \text { Body } \\
\text { mass index was calculated using weight in kilograms divided by the square of } \\
\text { the height in meters. } \ddagger \text { Smoking status: daily consumption (pack) } \times \text { duration of } \\
\text { smoking (year). HDL, high-density lipoprotein; LDL, low-density lipoprotein. } \S \\
\text { Chronic kidney disease was defined as an estimated glomerular filtration rate } \\
\text { less than } 60 \mathrm{~mL} / \mathrm{min} / 1.73 \mathrm{~m}^{2} .{ }^{*} \text { 2-tailed Student's t-test or } x^{2} \text { test. }\end{array}$} \\
\hline
\end{tabular}

eGFR.

Figure 1 shows the correlation between eGFR and carotid IMT by gender. The correlation coefficient between the eGFR and carotid IMT was significant in both men ( $r=-$ $0.210, \mathrm{p}<0.001)$ and women $(\mathrm{r}=-0.208, \mathrm{p}<0.001)$.

\section{Relationship between various risk factors including estimated glomerular filtration rate and carotid intima-media thickness}

Table 3 shows the relationship between the background characteristics and carotid IMT by gender. In men, age $(\mathrm{p}<$
$0.001)$, systolic blood pressure $(\mathrm{p}<0.001)$, antihypertensive drug use $(p<0.001)$, HDL-C $(p=0.006)$, LDL-C $(p=0.004)$, prevalence of diabetes $(\mathrm{p}=0.035)$ and eGFR $(\mathrm{p}<0.001)$ were significantly correlated with carotid IMT. In women, age $(\mathrm{p}<$ $0.001)$, systolic blood pressure $(\mathrm{p}<0.001)$, antihypertensive drug use $(\mathrm{p}<0.001)$, HDL-C $(\mathrm{p}=0.035)$, LDL-C $(\mathrm{p}=0.017)$ and eGFR $(\mathrm{p}<0.001)$ were significantly correlated with carotid IMT.

\section{Multiple linear regression analysis for carotid intima-media thickness}

In Model 1, stepwise multiple linear regression analysis 


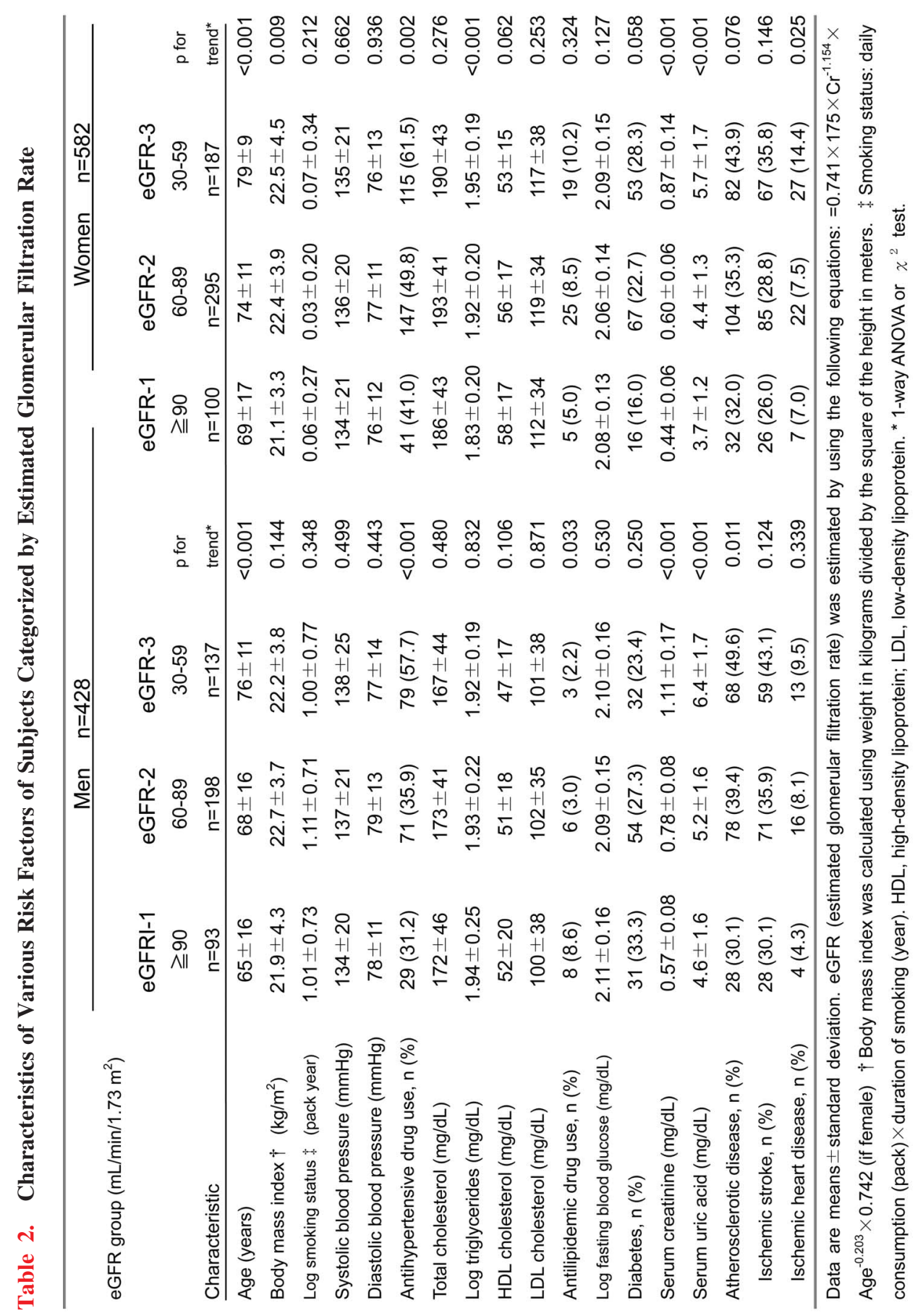

using IMT as an objective variable, adjusted for various risk factors as explanatory variables, showed that eGFR was a significant independent contributing factor along with known risk factors in men $(\beta,-0.096 ; \mathrm{p}=0.018)$ and women $(\beta$, 0.080; $\mathrm{p}=0.035$ ) (Table 4). In Model 2, antihypertensive drug use and antilipidemic drug use were added to eliminate the possible effect of medications along with the variables in Model 1, and Model 3 was adjusted for all risk factors by the forced entry method. The eGFR was a significant independent factor in men, but not in women. Moreover, in both men and women, in subjects without atherosclerotic disease, eGFR was not independently associated with carotid IMT. However, in subjects with atherosclerotic disease, eGFR was an independent risk factor for carotid IMT only in men $(\beta$, 0.169; $\mathrm{p}=0.019$ ) (data not shown).

\section{Discussion}

To examine the possible contribution of eGFR to advanced atherosclerosis, we studied the relationship between CVD risk factors, including eGFR and carotid IMT. This study showed that eGFR was independently related to carotid IMT evaluated by ultrasound. Increased carotid IMT occurred in parallel with the decline in renal function in patients with mild to moderate CKD. In addition, this study confirmed associations of early-stage CKD, which has been 


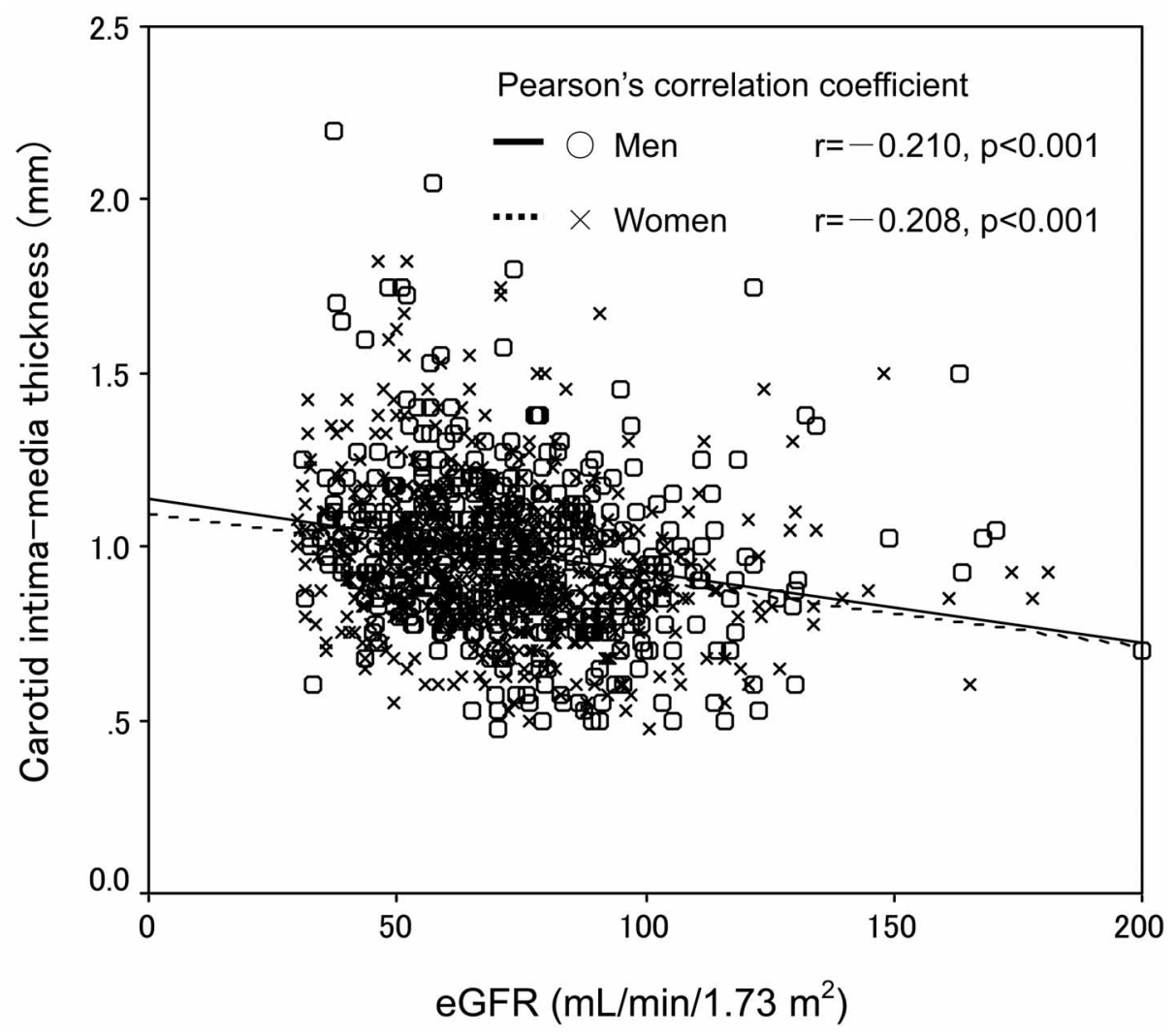

Figure 1. Relationship between eGFR (estimated glomerular filtration rate) and carotid intimamedia thickness by gender. eGFR (estimated glomerular filtration rate) $=0.741 \times 175 \times \mathrm{Cr}^{-1.154} \times$ $\operatorname{Age}^{-0.203} \times 0.742$ (if women).

defined as a creatinine-based estimated GFR (eGFR) of less than $60 \mathrm{~mL} / \mathrm{min} / 1.73 \mathrm{~m}^{2}(1)$ and carotid IMT. The risk associated with CKD was apparent in men and women in this study.

Previous studies including subjects at high risk for CVD consistently demonstrated an independent association between decreased level of renal function and CVD events as well as the mortality. However, the role of renal function as an independent risk factor remains controversial as reported in previous community-based studies $(6,10)$. Because of the different methods of estimating renal function used in the previous studies, direct comparisons between those studies are very difficult. Some studies have used serum creatinine concentrations as a marker of renal function $(6,16)$. Other studies have used the values based on the Cockcroft-Gault equation (16). Serum creatinine is the most widely used method of assessing renal function in clinical practice, although it has been established that serum creatinine alone is not correlated with true GFR (17), especially in older individuals (18). The Cockcroft-Gault equation has been shown to underestimate true GFR in very old patients, because of the strong effect of higher age on the estimating equation (19). In accordance with some recent studies $(10,20,21)$, we used the MDRD Study equation from GFR because it has been thoroughly validated in adults (22).

The relationship between carotid IMT and CKD has not been widely tested in subjects with early-stage CKD. In the Chinese population older than 40 years, carotid IMT has been reported to be significantly higher in subjects with early-stage CKD (eGFR 30 to $89 \mathrm{~mL} / \mathrm{min} / 1.73 \mathrm{~m}^{2}$ ) (10). eGFR and urinary albumin-creatinine ratio significantly correlated with carotid IMT in univariate analysis, however, this was not the case after adjusting for traditional cardiovascular risk factors. The greater prevalence of CVD risk factors in patients with CKD is reported to account for the higher carotid IMT. This study showed that the significant association between eGFR and carotid IMT provided direct evidence of the contribution of the decreased eGFR to advanced carotid atherosclerosis.

Some community-based longitudinal studies investigated the effect of renal function on cardiovascular and all-cause mortality. Rahman et al (21) reported that patients $\geq 55$ years with hypertension and one or more risk factors for coronary heart disease and reduced GFR are more likely to develop coronary heart disease than to develop end-stage renal disease. A low GFR of less than $53 \mathrm{~mL} / 1.73 \mathrm{~m}^{2}$ independently predicts increased risk of coronary heart disease (21). Muntner et al (23) investigated the association between eGFR and CVD-related and all-cause mortality rates during 16 years of follow-up monitoring from the Second National Health and Nutrition Examination Survey Mortality Study. Compared with subjects with eGFR $\geq 90 \mathrm{~mL} / \mathrm{min}$, those 
Table 3. Relationship between Various Risk Factors Including Estimated Glomerular Filtration Rate and Carotid Intima-Media Thickness

\begin{tabular}{|c|c|c|c|c|}
\hline \multirow{3}{*}{ Characteristic } & \multicolumn{4}{|c|}{ Pearson's correlation coefficient } \\
\hline & \multicolumn{2}{|c|}{ Men $n=428$} & \multicolumn{2}{|c|}{ Women $\mathrm{n}=582$} \\
\hline & r & $p$-value & r & p-value \\
\hline Age (years) & 0.540 & $<0.001$ & 0.463 & $<0.001$ \\
\hline Body mass index $\uparrow\left(\mathrm{kg} / \mathrm{m}^{2}\right)$ & -0.055 & 0.253 & -0.021 & 0.616 \\
\hline Log smoking status \$ (pack year) & 0.070 & 0.151 & -0.034 & 0.409 \\
\hline Systolic blood pressure $(\mathrm{mmHg})$ & 0.197 & $<0.001$ & 0.188 & $<0.001$ \\
\hline Diastolic blood pressure $(\mathrm{mmHg})$ & -0.031 & 0.526 & -0.024 & 0.567 \\
\hline Antihypertensive drug use $(\mathrm{Yes}=1, \mathrm{No}=0)$ & 0.234 & $<0.001$ & 0.162 & $<0.001$ \\
\hline Log triglycerides (mg/dL) & -0.046 & 0.338 & 0.063 & 0.129 \\
\hline HDL cholesterol (mg/dL) & -0.133 & 0.006 & -0.088 & 0.035 \\
\hline LDL cholesterol (mg/dL) & 0.138 & 0.004 & 0.099 & 0.017 \\
\hline Antilipidemic drug use $(\mathrm{Yes}=1, \mathrm{No}=0)$ & 0.047 & 0.327 & -0.010 & 0.808 \\
\hline Log fasting blood glucose (mg/dL) & -0.022 & 0.655 & 0.081 & 0.050 \\
\hline Diabetes $(Y e s=1, \mathrm{No}=0)$ & 0.102 & 0.035 & 0.059 & 0.156 \\
\hline eGFR $\left(\mathrm{mL} / \mathrm{min} / 1.73 \mathrm{~m}^{2}\right) \S$ & -0.210 & $<0.001$ & -0.208 & $<0.001$ \\
\hline
\end{tabular}

$\uparrow$ Body mass index was calculated using weight in kilograms divided by the

square of the height in meters. $¥$ Smoking status: daily consumption (pack) $\times$

duration of smoking (year). HDL, high-density lipoprotein; LDL, low-density

lipoprotein. $\S$ eGFR (estimated glomerular filtration rate) $=0.741 \times 175 \times \mathrm{Cr}^{-1.154}$

$\times \mathrm{Age}^{-0.203} \times 0.742$ (if woman).

with eGFR $<70 \mathrm{~mL} / \mathrm{min}$ exhibited higher relative risks of death from CVD and all causes [hazard ratio (HR), 1.68; $95 \%$ confidence interval (CI), 1.33 to 2.13 ] and 1.51 (95\% CI, 1.19 to 1.91$)$, respectively] in multivariate analyses. Weiner et al (24) demonstrated from a pooled analysis of recent community-based studies that CKD, which was defined as a GFR between 15 and $60 \mathrm{~mL} / \mathrm{min} / 1.73 \mathrm{~m}^{2}$, is a risk factor for the composite outcome of CVD and all-cause mortality (HR, $1.19 ; 95 \% \mathrm{CI}, 1.07$ to 1.32$)$ in the general population. This risk factor was more pronounced in Blacks than in Whites (24). Meisinger et al (4) confirmed the association of reduced eGFR and increased risk of CVD mortality in a large population-based study. It may be that the effect of $\mathrm{CKD}$ on atherosclerosis is evident.

The reasons for the high CVD risk in patients with $\mathrm{CKD}$ remain unknown. A possible explanation is that decreased renal function may be associated with other non-traditional risk factors that were not evaluated in this study. Such factors include uric acid, homocysteine (25), C-reactive protein (26), albuminuria (27), oxidative stress (28), endothelial dysfunction (29) and cytokines (30). Chronic kidney disease may be complicated by both duration and severity of other causes of CVD, and exacerbate atherosclerosis caused by
CVD risk factors. The duration of exposure to adverse CVD risk factors may be the largest in patients with pronounced CKD.

However, interpreting our results has several limitations that must be considered. First, based on its cross-sectional study design, the present findings are inherently limited in the ability to eliminate causal relationships between risk factors and carotid atherosclerosis. Secondly, since all subjects were hospitalized patients, we could not eliminate the possible effect of underlying diseases and medications used for hypertension and dyslipidemia on the present findings. Third, secondary prevention interventions in obesity, hypertension, dyslipidemia and diabetes mellitus may be successful in reducing risk factors, thus attenuating the observed association of risk factors with disease. Fourth, our definition of eGFR is based on a single assessment of serum creatinine and this may introduce misclassification bias. Therefore the demographics and referral source may limit ability to generalize.

In conclusion, the present study showed that eGFR is strongly associated with an increased prevalence of carotid atherosclerosis in both men and women. The underlying mechanism behind this relationship is unclear, but it seems 
Table 4. Multiple Linear Regression Analysis for Carotid Intima-media Thickness

\begin{tabular}{|c|c|c|c|c|c|c|}
\hline \multirow[b]{2}{*}{ Characteristic } & \multirow{2}{*}{$\begin{array}{r}\text { Men } \\
\text { Model } 1\end{array}$} & \multicolumn{2}{|c|}{$n=428 \quad \beta$ (p-value $)$} & \multirow[t]{2}{*}{ Women } & $n=582$ & $\beta$ (p-value) \\
\hline & & Model 2 & Model 3 & & Model 2 & Model 3 \\
\hline Age (years) & $0.515(<0.001)$ & $0.505(<0.001)$ & $0.459(<0.001)$ & $0.424(<0.001)$ & $0.419(<0.001)$ & $0.405(<0.001)$ \\
\hline Body mass index $\dagger\left(\mathrm{kg} / \mathrm{m}^{2}\right)$ & ------- & ------ & $-0.045(0.322)$ & ----- & ------ & $-0.045(0.259)$ \\
\hline Log smoking status $!$ (pack year) & --- & - & $0.058(0.145)$ & --- & - & $0.007(0.838)$ \\
\hline Systolic blood pressure $(\mathrm{mmHg})$ & $0.094(0.021)$ & $0.086(0.036)$ & $0.162(0.002)$ & $0.184(<0.001)$ & $0.173(<0.001)$ & $0.191(<0.001)$ \\
\hline Diastolic blood pressure $(\mathrm{mmHg})$ & --- & & $-0.078(0.126)$ & $-0.099(0.018)$ & $-0.094(0.026)$ & $-0.096(0.023)$ \\
\hline Antihypertensive drug use $(Y e s=1, N o=0)$ & ----- & $0.046(0.276)$ & $0.042(0.329)$ & ------ & $0.048(0.206)$ & $0.049(0.197)$ \\
\hline Log triglycerides $(\mathrm{mg} / \mathrm{dL})$ & $-1-$ & -- & $-0.027(0.554)$ & - & --- & $-0.003(0.949)$ \\
\hline HDL cholesterol (mg/dL) & ------ & ----- & $-0.063(0.131)$ & ------ & ---- & $-0.069(0.080)$ \\
\hline LDL cholesterol (mg/dL) & $0.132(0.001)$ & $0.130(0.001)$ & $0.151(<0.001)$ & $0.116(0.001)$ & $0.114(0.002)$ & $0.117(0.003)$ \\
\hline Antilipidemic drug use (Yes=1, No=0) & ----- & $0.009(0.814)$ & $0.018(0.646)$ & ------ & $-0.008(0.822)$ & $-0.009(0.812)$ \\
\hline Log fasting blood glucose (mg/dL) & ------ & ---- & $-0.072(0.133)$ & ----- & ---- & $0.053(0.189)$ \\
\hline Diabetes $($ Yes $=1, \mathrm{No}=0)$ & $0.100(0.012)$ & $0.095(0.019)$ & $0.137(0.004)$ & ----- & --- & $0.017(0.684)$ \\
\hline eGFR $\left(\mathrm{mL} / \mathrm{min} / 1.73 \mathrm{~m}^{2}\right) \S$ & $-0.096(0.018)$ & $-0.090(0.029)$ & $-0.096(0.019)$ & $-0.080(0.035)$ & $-0.074(0.050)$ & $-0.072(0.067)$ \\
\hline $\mathrm{R}^{2}$ & $0.345(<0.001)$ & $0.347(<0.001)$ & $0.366(<0.001)$ & $0.262(<0.001)$ & $0.264(<0.001)$ & $0.272(<0.001)$ \\
\hline
\end{tabular}

$\dagger$ Body mass index was calculated using weight in kilograms divided by the square of the height in meters. $\$$ Smoking status: daily consumption (pack) $\times$ duration of smoking (year). HDL, high-density lipoprotein; LDL, low-density lipoprotein. $§$ eGFR (estimated glomerular filtration rate) $=0.741 \times 175 \times \mathrm{Cr}^{-1.154} \times \mathrm{Age}^{-0.203} \times 0.742$ (if female). $\mathrm{R}^{2}$, multiple coefficient of determination. $\beta$, standard regression coefficient. Model 1, stepwise method. Model 2 and Model 3, forced entry method.

to be independent from traditional cardiovascular risk factors such as age, BMI, smoking, hypertension, dyslipidemia and diabetes. Estimation of GFR in addition to the consideration of present conventional risk factors may be useful for individual risk assessment. Further prospective population-based studies are needed to investigate the mechanisms underlying this association.

\section{Acknowledgement}

This study was supported, in part, by a grant-in-aid for Research Funds of Protracted-Life Society Promotion from the Foundation for the Development of the Community, Tochigi, Japan (2007).

\section{References}

1. Levey AS, Eckardt KU, Tsukamoto Y, et al. Definition and classification of chronic kidney disease: a position statement from Kidney Disease: Improving Global Outcomes (KDIGO). Kidney Int 67: 2089-2100, 2005.

2. Imai E, Horio M, Iseki K, et al. Prevalence of chronic kidney disease (CKD) in the Japanese general population predicted by the MDRD equation modified by a Japanese coefficient. Clin Exp Nephrol 11: 156-163, 2007.

3. Weiner DE, Tighiouart H, Stark PC, et al. Kidney disease as a risk factor for recurrent cardiovascular disease and mortality. Am J Kidney Dis 44: 198-206, 2004.

4. Meisinger C, Doring A, Lowel H. KORA Study Group. Chronic kidney disease and risk of incident myocardial infarction and allcause and cardiovascular disease mortality in middle-aged men and women from the general population. Eur Heart J 27: 12451250, 2006.

5. Culleton BF, Larson MG, Wilson PW, Evans JC, Parfrey PS, Levy D. Cardiovascular disease and mortality in a community-based cohort with mild renal insufficiency. Kidney Int 56: 2214-2219, 1999.

6. Garg AX, Clark WF, Haynes RB, House AA. Moderate renal insufficiency and the risk of cardiovascular mortality: results from the NHANES I. Kidney Int 61: 1486-1494, 2002.

7. Ishimura E, Shoji T, Emoto M, et al. Renal insufficiency accelerates atherosclerosis in patients with type 2 diabetes mellitus. Am J
Kidney Dis 38: S186-S190, 2001.

8. Shoji T, Emoto M, Tabata T, et al. Advanced atherosclerosis in predialysis patients with chronic renal failure. Kidney Int 61: 2187-2192, 2002.

9. Preston E, Ellis MR, Kulinskaya E, Davies AH, Brown EA. Association between carotid artery intima-media thickness and cardiovascular risk factors in CKD. Am J Kidney Dis 46: 856-862, 2005.

10. Zhang L, Zhao F, Yang Y, et al. Association between carotid arteryintima-media thickness and early-stage CKD in a Chinese population. Am J Kidney Dis 49: 786-792, 2007.

11. Friedewald WT, Levy RI, Fredrickson DS. Estimation of the concentration of low-density lipoprotein cholesterol in plasma, without use of the preparative ultracentrifuge. Clin Chem 18: 499-502, 1972.

12. Levey AS, Coresh J, Greene T, et al. Chronic kidney disease epidemiology collaboration. Using standardized serum creatinine values in the modification of diet in renal disease study equation for estimating glomerular filtration rate. Ann Intern Med 145: 247254, 2006.

13. Imai E, Horio M, Nitta K, et al. Modification of the MDRD Study equation for Japan. Am J Kidney Dis 11: 923-927, 2007.

14. Sdhu PS, Desai SR. A simple and reproducible method for assessing intima-media thickness of the common carotid artery. Br J Radiol 70: 85-89, 1997. 
15. Salonen JT, Salonen R. Ultrasonographically assessed carotid morphology and the risk of coronary heart disease. Arterioscler Thromb 11: 1245-1249, 1991.

16. Henry RM, Kostense PJ, Bos G, et al. Mild renal insufficiency is associated with increased cardiovascular mortality: The Hoorn Study. Kidney Int 62: 1402-1407, 2002.

17. Shemesh O, Golbetz H, Kriss JP, Myers BD. Limitations of creatinine as a filtration marker in glomerulopathic patients. Kidney Int 28: 830-838, 1985.

18. Giannelli SV, Patel KV, Windham BG, Pizzarelli F, Ferrucci L, Guralnik JM. Magnitude of underascertainment of impaired kidney function in older adults with normal serum creatinine. J Am Geriatr Soc 55: 816-283, 2007.

19. Froissart M, Rossert J, Jacquot C, Paillard M, Houillier P. Predictive performance of the modification of diet in renal disease and Cockcroft-Gault equations for estimating renal function. J Am Soc Nephrol 16: 763-773, 2005.

20. Zhang L, Zuo L, Wang F, et al. Cardiovascular disease in early stages of chronic kidney disease in a Chinese population. J Am Soc Nephrol 17: 2617-2621, 2006.

21. Rahman M, Pressel S, Davis BR, et al; ALLHAT Collaborative Research Group. Cardiovascular outcomes in high-risk hypertensive patients stratified by baseline glomerular filtration rate. Ann Intern Med 144: 172-180, 2006.

22. Levey AS, Coresh J, Balk E, et al. National Kidney Foundation. National Kidney Foundation practice guidelines for chronic kidney disease: evaluation, classification, and stratification. Ann Intern Med 139: 137-147, 2003.
23. Muntner P, He J, Hamm L, Loria C, Whelton PK. Renal insufficiency and subsequent death resulting from cardiovascular disease in the United States. J Am Soc Nephrol 13: 745-753, 2002.

24. Weiner DE, Tighiouart H, Amin MG, et al. Chronic kidney disease as a risk factor for cardiovascular disease and all-cause mortality: a pooled analysis of community-based studies. J Am Soc Nephrol 15: 1307-1315, 2004.

25. Homocysteine Studies Collaboration. Homocysteine and risk of ischemic heart disease and stroke: a meta-analysis. JAMA $\mathbf{2 8 8}$ : 2015-2022, 2002.

26. Ridker PM, Rifai N, Rose L, Buring JE, Cook NR. Comparison of C-reactive protein and low-density lipoprotein cholesterol levels in the prediction of first cardiovascular events. $\mathrm{N}$ Engl $\mathrm{J}$ Med 347: 1557-1565, 2002.

27. Gerstein HC, Mann JF, Yi Q, et al. Albuminuria and risk of cardiovascular events, death, and heart failure in diabetic and nondiabetic individuals. JAMA 286: 421-426, 2001.

28. Drueke T, Witko-Sarsat V, Massy Z, et al. Iron therapy, advanced oxidation protein products, and carotid artery intima-media thickness in end-stage renal disease. Circulation 106: 2212-2217, 2002.

29. Zoccali $C$, Benedetto FA, Maas $R$, et al. CREED Investigators. Asymmetric dimethylarginine, C-reactive protein, and carotid intima-media thickness in end-stage renal disease. J Am Soc Nephrol 13: 490-496, 2002.

30. Honda H, Qureshi AR, Heimburger O, et al. Serum albumin, Creactive protein, interleukin 6 , and fetuin a as predictors of malnutrition, cardiovascular disease, and mortality in patients with ESRD. Am J Kidney Dis 47: 139-148, 2006.

(C) 2008 The Japanese Society of Internal Medicine http://www.naika.or.jp/imindex.html 